\title{
Multiscale Strain Transfer in Cartilage
}

\author{
Manuela A. Boos ${ }^{1}$, Shireen R. Lamandé ${ }^{2,3}$ and Kathryn S. Stok ${ }^{1 *}$ \\ ${ }^{1}$ Department of Biomedical Engineering, The University of Melbourne, Parkville, VIC, Australia, ${ }^{2}$ Musculoskeletal Research, \\ Murdoch Children's Research Institute, Parkville, VIC, Australia, ${ }^{3}$ Department of Paediatrics, The University of Melbourne, \\ Parkville, VIC, Australia
}

OPEN ACCESS

Edited by:

Selwin K. Wu,

National University of Singapore, Singapore

Reviewed by:

Corey Neu,

University of Colorado Boulder,

United States

Christian Hiepen,

Freie Universität Berlin, Germany

*Correspondence:

Kathryn S. Stok

kstok@unimelb.edu.au

Specialty section:

This article was submitted to

Cell Adhesion and Migration,

a section of the journal

Frontiers in Cell and Developmental

Biology

Received: 15 October 2021

Accepted: 19 January 2022

Published: 04 February 2022

Citation:

Boos MA, Lamandé SR and Stok KS (2022) Multiscale Strain Transfer

in Cartilage.

Front. Cell Dev. Biol. 10:795522.

doi: $10.3389 /$ fcell.2022.795522
The transfer of stress and strain signals between the extracellular matrix (ECM) and cells is crucial for biochemical and biomechanical cues that are required for tissue morphogenesis, differentiation, growth, and homeostasis. In cartilage tissue, the heterogeneity in spatial variation of ECM molecules leads to a depth-dependent nonuniform strain transfer and alters the magnitude of forces sensed by cells in articular and fibrocartilage, influencing chondrocyte metabolism and biochemical response. It is not fully established how these nonuniform forces ultimately influence cartilage health, maintenance, and integrity. To comprehend tissue remodelling in health and disease, it is fundamental to investigate how these forces, the ECM, and cells interrelate. However, not much is known about the relationship between applied mechanical stimulus and resulting spatial variations in magnitude and sense of mechanical stimuli within the chondrocyte's microenvironment. Investigating multiscale strain transfer and hierarchical structure-function relationships in cartilage is key to unravelling how cells receive signals and how they are transformed into biosynthetic responses. Therefore, this article first reviews different cartilage types and chondrocyte mechanosensing. Following this, multiscale strain transfer through cartilage tissue and the involvement of individual ECM components are discussed. Finally, insights to further understand multiscale strain transfer in cartilage are outlined.

Keywords: cartilage, chondrocytes, mechanotransduction, tissue strain, ECM, heterogeneity

\section{INTRODUCTION}

All tissues in the body contain cells and a well organised extracellular matrix (ECM) compartment. The ECM is tissue-specific and the constituents, such as collagens, proteoglycans (PGs), and elastin, vary between different tissues. The ECM provides physical support and scaffolding for the cells, and also regulates crucial biochemical and biomechanical cues that are required for tissue morphogenesis, differentiation, growth, and homeostasis (Frantz et al. 2010; Theocharis et al. 2016). The cells within these tissues establish the ECM during development, maintain it in healthy tissue, and repair it in response to disease and injury (Lu et al. 2011; Humphrey et al. 2014). This reciprocal relationship between the cells and the ECM is based on the ability of cells to sense physical signals and transduce them into biochemical responses. Converting mechanical signals into chemical signals is called mechanotransduction (Mofrad et al. 2010; Wang 2017). Cross talk between cells and ECM creates a local environment where matrix stiffness and the physical forces sensed by the cells play an essential role in biological functions of cell and tissue physiology, and lead to constant tissue remodelling. Given the finite life span of cells and ECM components, this remodelling ensures a homeostatic balance in the tissue, e.g. structural integrity and functionality. This homeostasis is thus achieved by balanced matrix degradation and deposition of new 
constituents. Disruption of these homeostatic processes leads to tissue degeneration, fibrosis or other pathologies.

Cartilage is a connective tissue providing mechanical and structural support in different anatomical locations in the human body. Its ECM is produced by the relatively scarce specialised cells, chondrocytes, and is mainly composed of PGs, different collagen types, and elastin. It is classified into three different types, hyaline cartilage (articular joints, nose, ribs), elastic cartilage (ears, larynx), and fibrocartilage (menisci, intervertebral discs). These different types vary in their histological and physiological appearance and also in the magnitude of physical daily load they experience (Homicz et al. 2003; Heinegard et al. 2011; McNulty et al. 2015; Nimeskern et al. 2015). Furthermore, different cartilage types have a distinct ECM composition, with a highly heterogeneous accumulation of different proteins, molecules, and fibres. This variation in tissue composition between cartilage types leads to heterogeneous transfer of mechanical stimuli and influences cell morphology and biochemical response. Our knowledge about the mechanoresponse of cartilage has tremendously increased. Single cell responses to mechanical stimuli are well studied in health and disease. However, mechanical signals do not originate in the immediate vicinity of the cells. Rather they result from movements of the whole body and forces from body weight and joint movement. Even though we know well how chondrocytes respond to mechanical stimuli, we do not fully understand how these signals reach the cells, as it is a multiscale process. Furthermore, it is not well known how different ECM compositions and arrangements influence load transfer to cells. Specifically, how heterogeneous strain in the ECM influences chondrocytes and therefore long-term remodelling of cartilage in both health and disease, is not known.

Understanding these processes and mechanisms is as critical to progress in tissue regeneration and repair strategies as it is to engineering cartilage tissues. Gaining further insights into multiscale strain transfer and mechanotransduction in different cartilage types would provide a benchmark by which to compare tissue engineered constructs, and feed into developing effective treatment strategies to address cartilage pathologies. Therefore, this article first reviews different cartilage types and chondrocyte mechanosensing. Following this, multiscale strain transfer through cartilage tissue and the involvement of individual ECM components are discussed. Finally, insights to further understand multiscale strain transfer in cartilage are outlined.

\section{DIFFERENT CARTILAGE TYPES}

\section{Hyaline Cartilage}

In hyaline cartilage, the so-called 'solid' phase of the ECM is mainly composed of collagen II (15\%-22\%) and PGs (4\%-7\%). The PGs are comprised of different glycosaminoglycans (GAG) chains attached to a core protein. The fluid phase on the other hand consists of up to $80 \%$ water (Eyre 2002; Heinegard 2009; Sophia Fox et al. 2009). This water content is a result of the fixed charge density created by the negatively charged sulphated GAGs.
Their charge attracts cations which leads to osmotic pressure in the tissue. As the PGs with the attached GAGs swell, they are physically limited by the collagen network which gives articular cartilage a high compressive resilience. This feature is further increased under physical load as the repulsive forces of the PGs are pushed closer together and swelling is hindered by the tension in the collagen fibres (Roth et al. 1980). This effect enables articular cartilage to withstand significant loads up to multiple times body weight (Mansour, 2003; Lu et al. 2009; Sophia Fox et al. 2009; Thielen et al. 2019). The experienced physical load of the cartilage varies depending on anatomical location.

Articular cartilage is divided into a superficial zone, a middle zone, and a deep zone, which vary in their ECM composition, cell orientation and morphology (Figure 1). In the superficial zone chondrocytes are more abundant and have a flattened, elongated form compared to the deeper zones where they are less densely populated. In deeper zones the chondrocytes are more spherical and are arranged in columns. The PG content in articular cartilage increases with depth. The collagen content however remains constant with increasing depth, but fibres change from being arranged parallel to the surface in the superficial zone to a perpendicular orientation in the deeper zones (Eggli et al. 1988; Guilak, 1995; Wong et al. 1996; Poole et al. 2001; Athanasiou et al. 2009; Quinn et al. 2013). Elastin is present in the superficial zone of articular cartilage (Mansfield et al. 2009). The elastin fibres run parallel to the surface and roughly in the same direction as the collagen fibres (Yeh et al. 2005; Yu et al. 2010).

All chondrocytes in the tissue are surrounded by a PG-rich pericellular matrix (PCM) (Figure 1) (Poole 1997). The PCM has a crucial function in absorbing, redistributing, and transmitting mechanical forces in articular and meniscal cartilage (Poole 1997; Sanchez-Adams et al. 2013; Gilbert et al. 2018) (Millward-Sadler et al. 2004). It shields chondrocytes from extensive stress, and because it is a direct link between the cells and the ECM makes an important contribution to transmitting biomechanical signals to the cells (Quinn et al. 1998). The PCM has a high concentration of aggrecan and other PGs such as perlecan, biglycan and decorin which play an important role in its integrity (Gomes et al. 2002; Vincent et al. 2007; Wilusz et al. 2014; Shu et al. 2016). In addition to PGs, collagen type VI in articular cartilage is highly concentrated in the PCM and plays an important role in its mechanical integrity. It connects the chondrocytes to the PCM through $\beta$-integrin receptors and transmembrane PGs (Marcelino et al. 1995; Wilusz et al. 2012). The PCM in the articular cartilage superficial zone also contains elastin and lipids (Poole 1997; Mansfield et al. 2009). As the tensile and shear stresses are higher in this zone, this composition would protect the chondrocytes from these stresses.

\section{Fibrocartilage}

Located in the knee joint, the menisci, composed of fibrocartilage (Figure 1), are responsible for increasing the contact area and distributing forces across the joint. In contrast to hyaline and elastic cartilage, the main collagen type in the menisci is type I (Fox et al. 2015). Collagen fibres are oriented circumferentially in the interior layers of meniscal cartilage compared to radially oriented fibres in the outer 


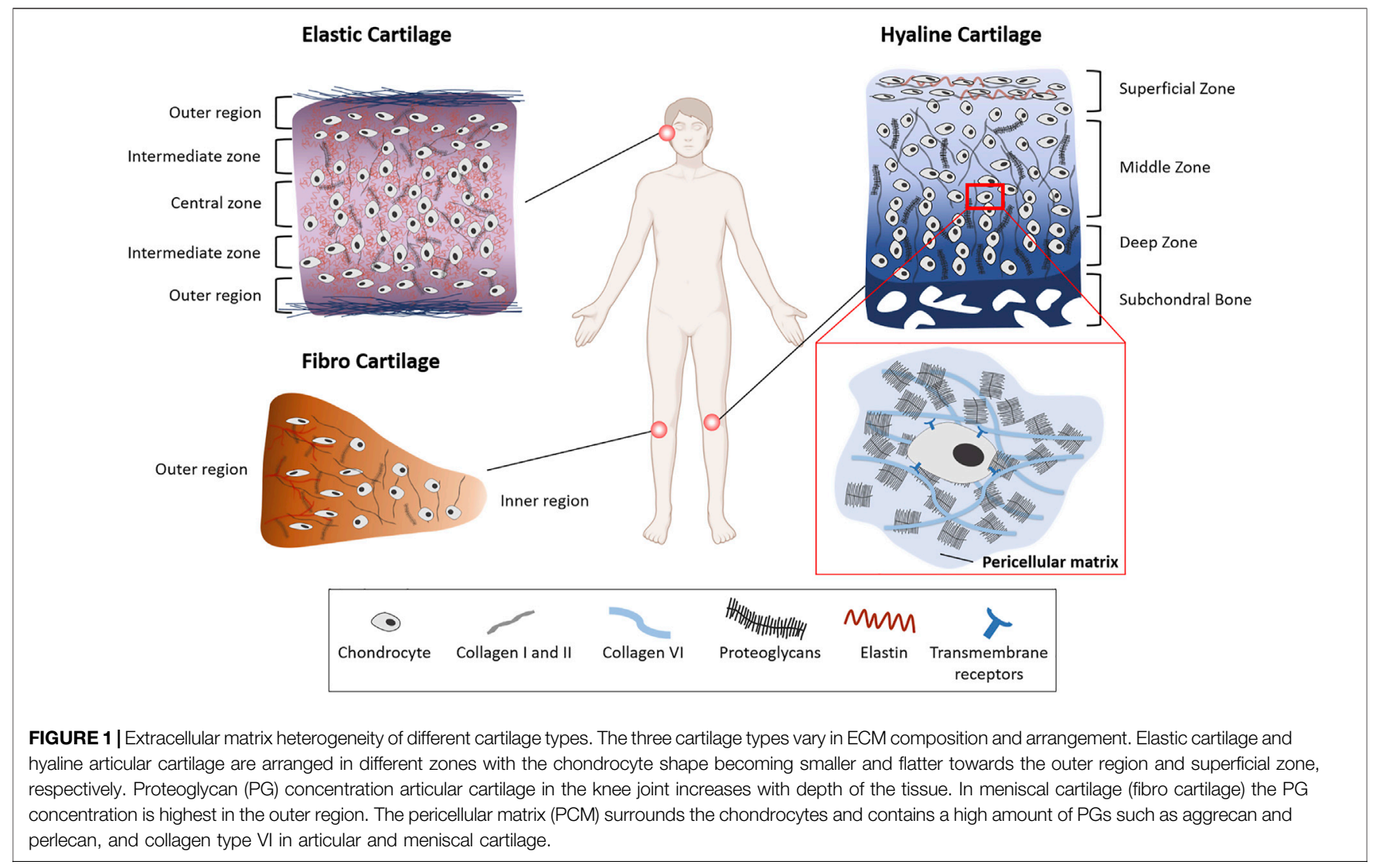

regions (Amis 2010). The circumferential alignment of these collagen fibres contributes to the load bearing properties of the menisci by converting compressive axial stresses to tensile hoop stresses (McDermott et al. 2008; Sanchez-Adams et al. 2013; Fox et al. 2015). Like articular chondrocytes, cells in meniscal cartilage differ in their appearance depending on their location within the tissue. Cells in the outer region of meniscal cartilage have an oval, fusiform shape, whereas cells in the inner region have a round shape (Hellio Le Graverand et al. 2001; Makris et al. 2011). In contrast to the large amount of collagen type I in outer regions of the meniscus, the inner region has more collagen type II (60\%) than type I (40\%) (McDermott, 2010; Sanchez-Adams et al. 2013). PG-rich regions are interspersed between these collagen fibres, leading to a highly inhomogeneous tissue (Upton et al. 2008; Han et al. 2013; Han et al. 2016). Similarly to the PCM in hyaline cartilage, the PCM in meniscal cartilage is mainly composed of perlecan and collagen type VI (Sanchez-Adams et al. 2013) (Figure 1).

\section{Elastic Cartilage}

Elastic cartilage is not exposed to large biomechanical forces, as it is found in the head and neck region. It contains a high amount of elastin which is arranged around the chondrocytes and contributes to maintaining anatomic shape via complex heterogeneous arrangement of tensile compressive fibre networks (Figure 1) (Culav et al. 1999; He et al. 2013; Nimeskern et al. 2016). Elastic ear cartilage is arranged in different zones as well. Similar to articular cartilage, the chondrocytes in the outer regions are smaller and flatter than the cells in the intermediate and central zones, where the chondrocytes are larger and further apart (Keith et al. 1977; Jessop et al. 2016). Collagen type II in auricular cartilage is arranged together with a dense elastin fibre network surrounding the chondrocytes in a honeycomb like structure (Chen et al. 2014; Bos et al. 2018). The composition of the PCM of elastic cartilage has not been reported.

Despite their differences in ECM structure, all three cartilage types are avascular (except the outer region of the menisci), aneural, and alymphatic, resulting in a tissue with limited intrinsic repair capabilities (Khan et al. 2008; Makris et al. 2011). These variations in the cartilage ECM make it a highly heterogeneous tissue on a macrostructural as well as microstructural level. These structural differences in cartilage types directly influence the mechanical environments experienced by the chondrocytes and this heterogeneity leads to nonuniform strain and stress in cartilage. This in turn, changes how mechanical signals are transmitted and received by the cells in these different tissues.

\section{CHONDROCYTE MECHANOSENSING}

Chondrocytes establish the cartilage ECM during development and maintain it in healthy tissue (Lu et al. 2011; Humphrey et al. 


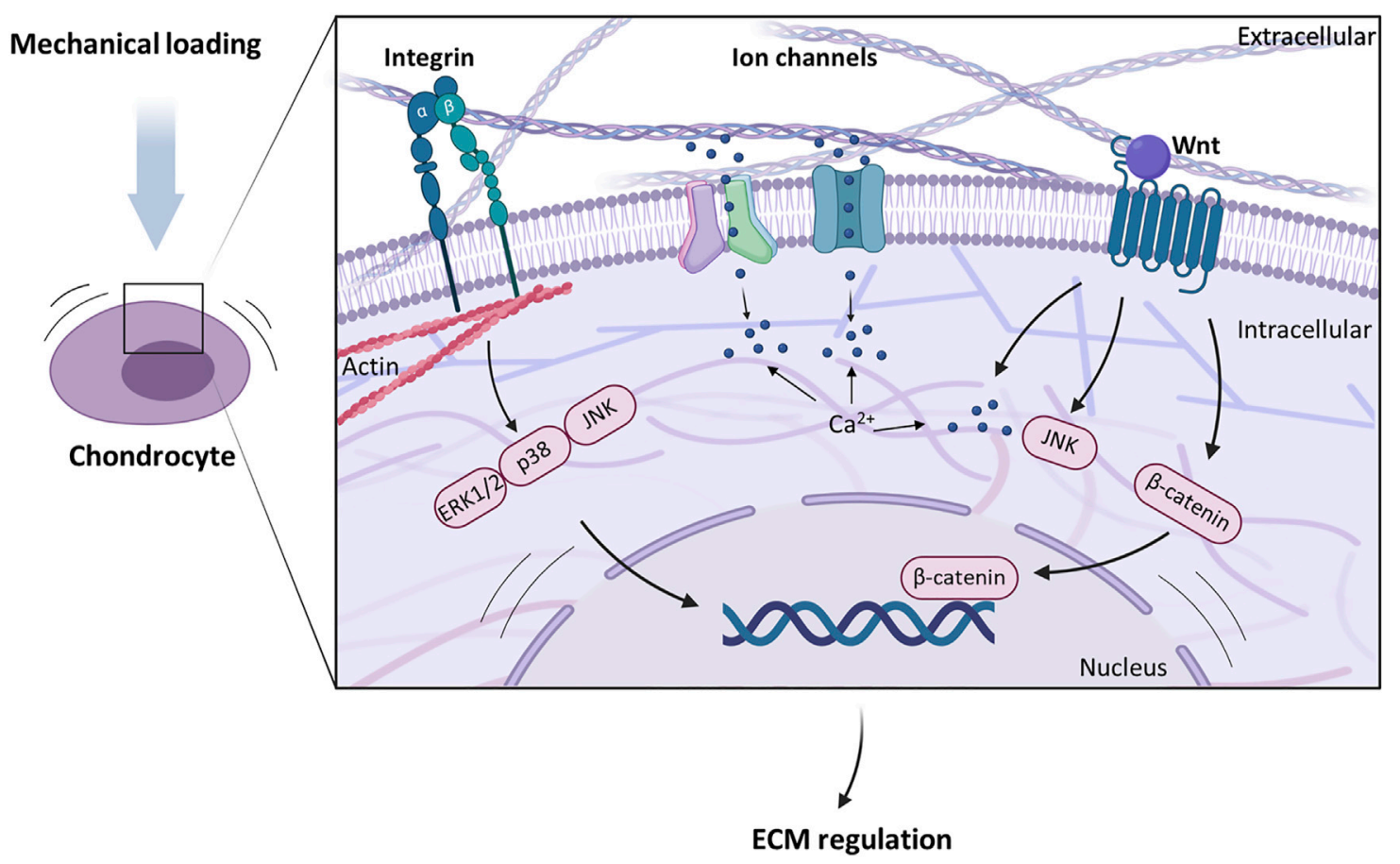

FIGURE 2 | Different cell membrane receptors and signalling molecules are involved in chondrocyte mechanotransduction. Transmembrane ion channels induce intracellular $\mathrm{Ca}^{2+}$ signalling upon mechanical stimulation of cartilage and regulate extracellular matrix (ECM) biosynthesis. Integrins serve as a link between ECM molecules and the cytoskeleton and lead to an activation of the MAPK pathway. Signalling molecules such as Wnt activate intracellular signalling cascades that are important for cartilage homeostasis.

2014). This reciprocal relationship between the chondrocytes and ECM is based on their ability to sense physical signals and transduce them into biochemical responses, making them highly mechanosensitive. This conversion of mechanical signals into chemical signals is called mechanotransduction (Mofrad et al. 2010; Wang 2017) and this allows chondrocytes to sense changes in ECM properties. The response of articular chondrocytes to mechanical stimuli is well studied. They have several cell surface mechanoreceptors, e.g. ion channels, integrin receptors, and primary cilia, that are sensitive to changes in intrinsic tissue stiffness and external tissue compression (Figure 2) and initiate intracellular signalling cascades that modulate gene expression leading to ECM remodelling (Gilbert et al. 2018). Furthermore, intracellular deformation and signalling molecules enable responses to changes in mechanical environment.

\section{Ion Channels}

Ion channels such as transient receptor potential vanilloid 4 (TRPV4) and Piezo channels are $\mathrm{Ca}^{2+}$-permeable and situated in the plasma membrane where they play a role in mechanically induced $\mathrm{Ca}^{2+}$ signalling. Mechanical perturbations such as changes in membrane tension, lipid bilayer distortion and osmotic stress activate these channels. This facilitates $\mathrm{Ca}^{2+}$ influx into the chondrocyte and initiates intracellular signalling pathways (Guilak et al. 1999; Pingguan-Murphy et al. 2006). TRPV4 is highly expressed in chondrocytes and promotes anabolic responses. It provides an essential link between mechanical loading and ECM synthesis (Phan et al. 2009; O'Conor et al. 2014; Zelenski et al. 2015). Piezo 1 and 2 channels however are involved in transducing hyperphysiological mechanical stimuli resulting from injuries or overload (Lee et al. 2014; Lee et al. 2017). Mechanical integrity of the ECM and mechanical stimuli experienced by the cells are therefore tightly related to the resulting cellular response.

\section{Integrins}

Integrins also play an important role in chondrocyte mechanosensing. They are a family of transmembrane proteins comprised of $\alpha$ and $\beta$ subunits. Their large extracellular domains bind to PCM ligands such as fibronectin and collagen type VI, whereas the cytoplasmic domains bind to the actin skeleton of the chondrocytes, making integrins a transmembrane link between ECM molecules and the cytoskeleton (Millward-Sadler et al. 2000; Hynes 2002; Wolfenson et al. 2013). Mechanical stimulation activates integrins, and also increases their expression in chondrocytes (Lucchinetti et al. 2004). Furthermore, cell death resulting from cartilage injuries and overload has been associated with integrin-mediated signalling. Integrins transduce mechanical signals from the ECM to the chondrocytes and are sensitive to changes in mechanical properties and stimuli.

The activation of integrins can result in activation and phosphorylation of mitogen-activated protein kinases 
(MAPKs). MAPKs comprise ERK1/2, p38 and JNK (Fitzgerald et al. 2008). Their activation leads to many intracellular processes like cell division, differentiation, apoptosis, and transcription. A shear strain of $3 \%$ applied at $0.1 \mathrm{~Hz}$ for up to $24 \mathrm{~h}$ has led to an activation of ERK $1 / 2$ and $\mathrm{p} 38 \mathrm{~K}$ in bovine cartilage explants. The inhibition of ERK1/2 or p38K however abolished the mechanically induced transcription of aggrecan and type II collagen (Fitzgerald et al. 2008). JNK is thought to have role in load-induced matrix anabolism. Cyclic loading at $0.33 \mathrm{~Hz}$ for up to $3 \mathrm{~h}$ induced JNK activation together with increased PG synthesis in human chondrocyte monolayers (Zhou et al. 2007).

\section{Primary Cilia}

Primary cilia are microtubule-based structures extending from the chondrocyte surface into the PCM where they sense matrix deformation and osmotic changes through integrins in the primary cilia membrane and extracellular matrix components, and through mechanosensing ion channels. (McGlashan et al. 2006; Ruhlen et al. 2014). In chondrocytes under 15\% compressive strain primary cilia were involved in upregulated PG synthesis (Wann et al. 2012). Furthermore, they have been shown to transduce mechanical signals via activation of the MAPK/ERK pathway. A loss of cilia leads to inhibition of downstream cartilage matrix gene expression such as type II collagen (COL-II), type X collagen (COL-X) and BMP-2 (Irianto et al. 2014). As a result, primary cilia play a crucial role in cartilage ECM formation.

\section{Intracellular Deformation}

Cytoskeletal organisation and cell shape likewise influence chondrocyte metabolism and activate intrinsic signalling (Ingber et al. 1994; Guilak 1995). Tissue compression as well as changed mechanical properties can lead to compressive deformation of the cellular components, including the nucleus, endoplasmic reticulum, cytoskeleton, and integrins (Guilak 1995; Mobasheri et al. 2002; Wong et al. 2003; Szafranski et al. 2004). These events either lead to direct changes in gene expression or protein synthesis or induce other signalling cascades like intracellular calcium signalling (D'Andrea et al. 2000; Guilak et al. 2000; Roberts et al. 2001; Martins et al. 2012; Hall 2019).

The actin skeleton and the vimentin network are responsible for cell integrity. Disrupting actin leads to a $90 \%$ reduction in cell stiffness (Trickey et al. 2004). Following actin disruption, nuclear height and shape are severely changed, which is likely to have an effect on the biochemical response of the cells (Guilak 1995; Martins et al. 2012). Furthermore, the actin skeleton is highly sensitive to mechanical stimulation. High hydrostatic pressure (15-30 MPa) can break down the actin network, and dynamic or static loading has resulted in actin remodelling in bovine chondrocyte monolayers (Parkkinen et al. 1995). This sensitivity of actin to loading and the resulting changes in cell stiffness likely influence chondrocyte gene expression and protein biosynthesis. The vimentin network is prominent in weightbearing areas of rabbit articular cartilage, whereas it is disassembled in unloaded rat articular cartilage explants (Eggli et al. 1988; Durrant et al. 1999). This suggests a similarly important role of vimentin in chondrocyte homeostasis (Blain et al. 2006).

\section{Wnt Signalling}

Biomechanical effects in cartilage are mediated through activating and/or suppressing intracellular signalling pathways. Wnts are a family of signalling molecules that are essential during chondrogenesis and chondrocyte homeostasis (Tamamura et al. 2005; Yuasa et al. 2008). Wnt is bound to the ECM, mainly to heparan sulphate, a specific GAG chain (Takada et al. 2017)and its activation is thought to occur through mechanical as well as enzymatic activity (Scholtes et al. 2018; Thielen et al. 2019). The downstream effects of Wnt ligands include translocation of $\mathrm{b}$-catenin to the nucleus to effect transcription, regulation of $\mathrm{Ca}^{2+}$ release, and cytoskeleton reorganisation. In vivo both excessive activation and lack of Wnt leads to cartilage breakdown, therefore the mechanoregulation of Wnt signalling is essential for cartilage integrity and homeostasis (Zhu et al. 2008; Zhu et al. 2009; Nalesso et al. 2011).

\section{Mechanosensing in Meniscal Cartilage}

How chondrocytes in meniscal cartilage respond to mechanical forces remains largely unknown. Like articular chondrocytes, meniscal chondrocytes are highly mechanosensitive. Physiological compression of porcine ex vivo meniscus explants at a strain rate of $10 \%$ increases aggrecan gene expression (Aufderheide et al. 2006; Zielinska et al. 2009). However, 20\% strain induces a catabolic response and increased PG breakdown (McHenry et al. 2006; Zielinska et al. 2009). Even though we have gained more insight into biochemical activities in meniscal cartilage under load, many underlying mechanisms still need to be investigated.

\section{Mechanosensing in Elastic Cartilage}

Elastic cartilage is not exposed to constant high loading, and so, although they are mechanosensitive, mechanotransduction processes in elastic cartilage chondrocytes have not been established. When subjected to dynamic compression, porcine auricular chondrocytes upregulate collagen I, collagen II, and aggrecan gene expression (Chung et al. 2008); however, hese cells were seeded in hyaluronan hydrogels which do not mimic the native ECM components of elastic cartilage. An ECM that lacks elastin may therefore not be an ideal scaffold to study cellular response of chondrocytes from elastic cartilage. The influence of this distinct ECM in auricular cartilage on the chondrocytes remains to be investigated.

We have a good understanding of how articular chondrocytes respond to mechanical stimuli in vitro and which mechanosensitive channels, receptors and signalling pathways are activated upon stimulation. However, it is also essential to comprehend how stress and strain resulting from movement and body weight are transferred through the ECM to the cells in situ. Mechanical stimulation upregulates ECM biosynthesis and deposition. Therefore, there is likely a direct relationship between ECM composition, mechanical properties and resulting cellular response which should be further explored. 


\section{STRAIN TRANSFER AND INDIVIDUAL ECM COMPONENTS}

Body movements are complex resulting in different stresses and strains in all cartilage tissues. In the knee strains in articular cartilage can reach up to around $20 \%$ depending on the movements and are higher in more load bearing regions (Eckstein et al. 1999; Liu et al. 2010; Coleman et al. 2013). Even though compression is the main force experienced by joints, their movements also include sliding and rotation. Therefore, articular cartilage is also subjected to shear forces (Wong et al. 2008).

Meniscal cartilage is important for absorbing shock and distributes more than $50 \%$ of the axial load on the knee joint (Fukubayashi et al. 1980; Fithian et al. 1990). The strains measured in meniscal cartilage under physiological loading are in the range of 3-8\% (Kolaczek et al. 2016).

Strain transfer involves organs, tissues, and cells, originating at a macro level, then travelling through the tissues to reach the cells and elicit a response. The cartilage ECM is highly heterogeneous (Figure 1) ensuring that force transfer is a complex, nonlinear and nonuniform process.

\section{Bulk Cartilage Tissue Strain is Heterogeneous}

The heterogeneity in articular and fibrous cartilage leads to nonuniform compressive strain gradients that are depth-dependent (Eckstein et al. 1999; Erne et al. 2005; Upton et al. 2008). Articular cartilage explants exhibit distinct depth-dependent strain distributions in response to uniaxial compression. The tissue strain in the superficial layer is significantly higher compared to strain in the middle and deep zones in response to tensile and compressive forces (Erne et al. 2005; Mansfield et al. 2015). The higher compressive modulus in deeper zones of articular cartilage correlates with the higher PG content in these zones. Swelling pressure determines the tissue's response to compression. Therefore, in the superficial zone with a lower PG concentration, water is lost more easily as the swelling pressure is lower (Chen et al. 2001).

In meniscal cartilage, strain transfer through the tissue was also heterogeneous and tissue specific (Han et al. 2013). The strain was less attenuated through the tissue at low applied strains (3\%-6\%) and more attenuated with higher applied strains $(6 \%-15 \%)$.

In non-load bearing cartilage, i.e., elastic cartilage, the specific strain distribution has not been reported. Only the mechanical properties of the bulk tissue have been analysed (Nimeskern et al. 2016; Chang et al. 2020).

Despite our good understanding of the mechanics of different zones, the underlying mechanisms and micromechanics of the local tissue composition around the cells remain to be fully investigated. A wide range of cellular responses in the same zone of articular cartilage indicates that cells might not experience the same mechanical loading on a microscale level (Mansfield et al. 2015; Kwon et al. 2016). Microscale strain is also highly heterogeneous in fibrocartilage (Figure 3) (Mansfield et al.
2015; Han et al. 2016). Looking beyond bulk tissue mechanics has revealed mechanical loading produces highly heterogeneous microscale strains potentially influencing chondrocyte responses and tissue remodelling. Investigating this local microscale environment is key to unravelling how forces from tissue scale are transmitted to cell level. Therefore, exploring the contribution of the individual ECM components and their interaction under bulk load is essential to understand the micromechanics and investigate the influence of heterogeneous strain on tissue health and disease.

\section{Collagen}

Collagen fibres in articular cartilage have been widely explored in relation to tissue mechanics. They are able to resist very high tensile loads. Tensile modulus is largest in the direction parallel to the long axis of collagen fibres and up to 5 times higher in the superficial zone of articular cartilage compared to deeper zones (Figure 1). Tensile modulus is related to the degree of crosslinking between collagen fibres (Huang et al. 2005; Responte et al. 2007). In the superficial zone of articular cartilage, where collagen fibres are parallel to the surface, the strain following tensile load is highly heterogeneous. Tensile strain of $6 \%$ either applied along the main axis of the collagen fibres or transverse to the main collagen axis in the superficial zone resulted in heterogeneous strain distribution (Mansfield et al. 2015). This heterogeneity in the tensile strain field is thought to be due to the leaf-like organisation of the collagen layers (Nickien et al. 2013; Mansfield et al. 2015).

\section{Proteoglycans}

Under compression, the swelling pressure resulting from the GAGs is resisted by the tensile forces of the collagen fibres. The PG concentration increases with tissue depth (Figure 1) and correlates with the compressive modulus (Mansfield et al. 2015). On a microscale level, while Irwin et al. observed only a weak correlation between GAG content and strain magnitude (Irwin et al. 2021) they acknowledged it is difficult to distinguish GAGs from collagen fibres using Raman spectroscopy and so the measured strain might not have resulted from GAGs solely. Furthermore, strain transfer in PG-rich regions in meniscal cartilage was significantly attenuated compared to fibre rich regions which suggests an intimate and direct involvement of the PGs in strain attenuation and distribution (Han et al. 2016). Diseases like osteoarthritis are related to PG loss and impaired mechanical tissue integrity, which leads to a cascade of deteriorating events. Therefore, a clear understanding of the role of PGs in stress and strain transfer at the microscale is important.

\section{Elastin}

The elastin fibres in the superficial zone of articular cartilage are always under tension and a strain of around $15 \%$ even in unloaded tissue. Under compression, the fibres show minimal deformation or movement and there is no difference in compressive response when elastin is depleted from articular cartilage (Mansfield et al. 2015; Nimeskern et al. 2016). Therefore, elastic fibres are thought to be involved in recovery after shear and 


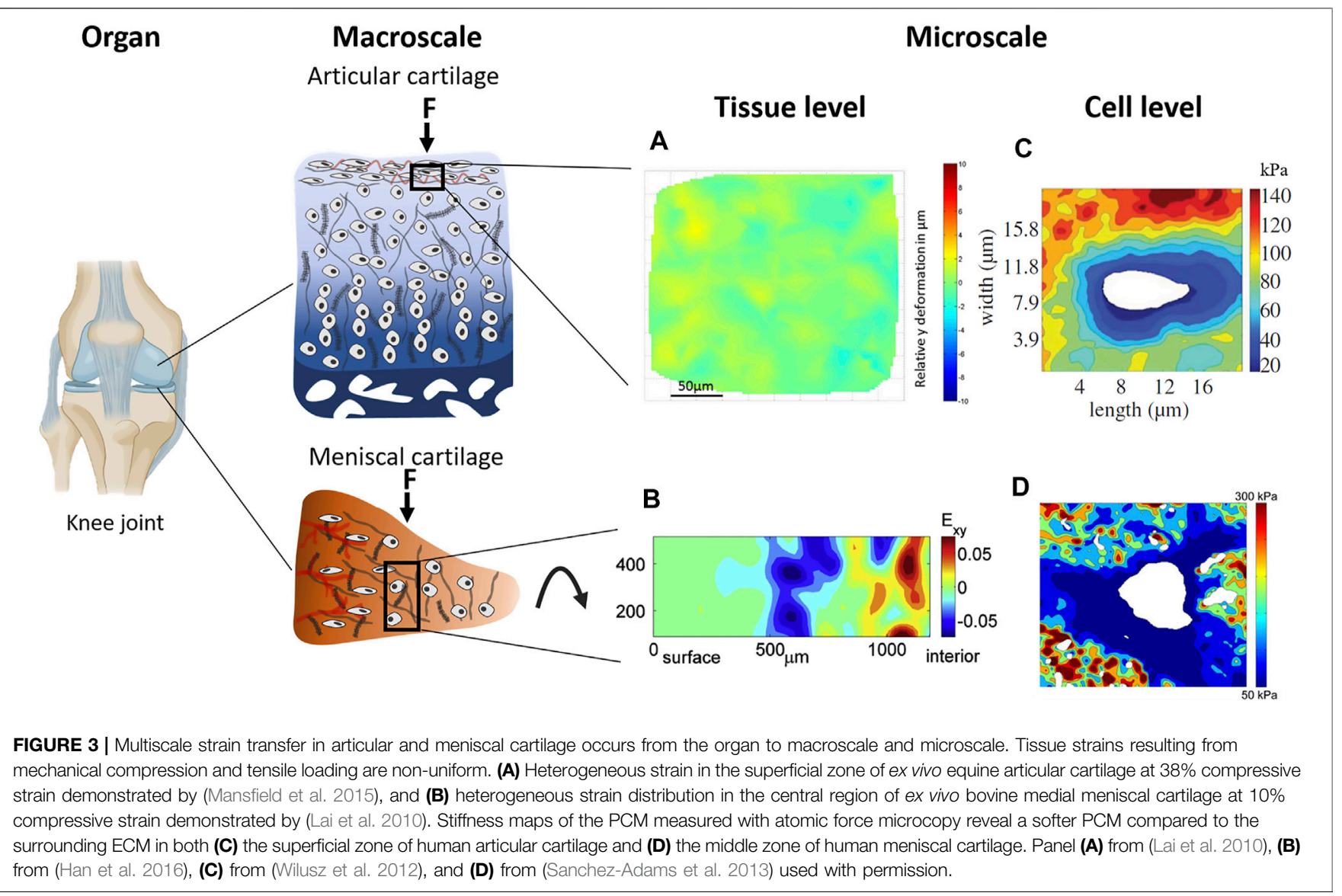

tensile stress (Mansfield et al. 2015). These stresses are highest in the superficial zone of articular cartilage, where the majority of the elastin fibres are present. In auricular cartilage, however, elastin is a major ECM component. Extensive mechanical evaluation has highlighted its importance in the viscoelastic response of auricular cartilage. The tissue loses its compressive and tensile integrity following elastin depletion (Nimeskern et al. 2016).

\section{Pericellular Matrix}

The high PG concentration in the PCM produces a high negative charge which attracts counterions therefore providing immediate $\mathrm{Ca}^{2+}$ sources for channel activation and swelling, giving it its distinct mechanical properties. The ECM in articular cartilage outside the PCM has a stiffness of up to $1000 \mathrm{kPa}$, whereas the stiffness of the PCM is only around $50 \mathrm{kPa}$ with a decrease of stiffness in towards deeper zones of the tissue (Figure 3) (Darling et al. 2010; Wilusz et al. 2012). In meniscal cartilage the PCM stiffness is around $150 \mathrm{kPa}$ in the outer region gradually decreasing towards the inner region where the stiffness is around $30 \mathrm{kPa}$ (Sanchez-Adams et al. 2013). The chondrocytes themselves have the lowest stiffness, which is $0.1 \mathrm{kPa}$ (Alexopoulos et al. 2003; Steklov et al. 2009; Darling et al. 2010; Nia et al. 2015; Carlson et al. 2017; Chery et al. 2020).

The PCM mechanical properties vary with changes in protein and PG composition. Reduced PG content results in a less negative environment and thus less $\mathrm{Ca}^{2+}$ leading to reduced osmotic swelling, ultimately changing the stiffness (Guilak et al. 2006; Danalache et al. 2019; Zhou et al. 2019; Chery et al. 2020). Intact PCMs exhibited a lower elastic modulus compared to PCMs that were depleted of perlecan and were mainly composed of collagen type VI (Wilusz et al. 2012). However, a lack of collagen type VI also decreases the PCM mechanical properties (Alexopoulos et al. 2009; Zelenski et al. 2015; Chery et al. 2020).

These changes in PCM mechanical properties directly influence the chondrocytes. Several studies have shown that a loss of the PCM or a decreased PG content in the PCM leads to increased cell deformation (Millward-Sadler et al. 2004) (Guilak et al. 2006; Danalache et al. 2019; Chery et al. 2020). Recent in silico studies have revealed that the softening of the PCM resulted in an increase of strain in the PCM as well as the chondrocyte, even when the macroscale mechanical properties of the tissue did not change (Khoshgoftar et al. 2017). This highlights the importance of the PCM in attenuating mechanical stress and strain shielding of the chondrocytes especially in the superficial zone of articular cartilage where stresses are higher. In a study subjecting bovine articular cartilage explants to hyperphysiological impact loading resulting in cell death due to high strain on integrins. However, when the cell-matrix adhesion was inhibited the cells did not die under injury loading (Sauter et al. 2012; Jang et al. 2014). 
Mechanical integrity of the PCM is necessary for physiological mechanotransduction and cartilage health. It is crucial in providing the right mechanical cues for chondrocytes homeostasis and is imperative for the cell-matrix connection. A change in mechanical properties of the PCM seems to have a more direct influence on the cells than bulk tissue strain. It is however not well understood how the heterogeneous strain from the tissue is received by the PCM on the microscale and how this impacts the cells.

\section{Chondrocytes}

There is evidence that the nonuniform ECM and resulting strain transfer through the tissue influences chondrocyte deformation and morphology. Cell shape is influenced by the ECM composition which is different in the different zones (Figure 1) (Benya 1988; Guilak, 1995). Chondrocytes in the superficial zone, where there is a lower compressive modulus, experience larger changes in volume compared to chondrocytes in the other zones (Mansfield et al. 2015). There can be a wide range of changes in cell thickness in the same zone under compression, indicating that even in the same zone, cells might not experience the same mechanical load (Mansfield et al. 2015; Kwon et al. 2016). Under compression no significant chondrocyte shape changes or displacement were detected in the plane parallel to the surface, whereas under tensile load, all chondrocytes deformed parallel to the articular surface. At a tissue strain of $38 \%$, the median compressive strain in the chondrocytes was 46\% (Mansfield et al. 2015). These deformation differences could be due to the original shape of the chondrocytes before mechanical stimulation. In meniscal cartilage, spherical cells deform less than elongated cells which readily deform (Han et al. 2013). Besides in vitro experiments, different in silico models have highlighted this relationship between cellular deformation and tissue heterogeneity (Breuls et al. 2002; Klika et al. 2019; Tanska et al. 2020).

In addition to variable changes in cell morphology, intracellular strains are also nonuniform. Chondrocyte deformation generates heterogeneous intracellular strain fields which appear to be dependent on cell organelle organisation (Knight et al. 2006). Cell nuclei deform less than the cytoplasm as they have a higher stiffness (Gilchrist et al. 2007). Chondrocyte metabolism is influenced by ECM composition and zonal arrangement (Benya 1988; Guilak et al. 1995; Hall 2019). Elevated strain magnitudes, especially in the superficial zone of articular cartilage, are associated with mitochondrial dysfunction, apoptosis, and cell death (Bonnevie et al. 2018). Although this demonstrates that the mechanical environment influences chondrocyte metabolism, it remains unknown what effects this has in the long term and how this heterogeneous strain affects tissue remodelling over time. Furthermore, it is unclear how stress and strain reach cells and are distributed through the whole heterogeneous tissue, and further how a change in matrix composition and integrity influences the forces sensed in the microenvironment of the cell.

\section{FURTHER DIRECTIONS AND OUTLOOK}

The transfer of stress and strain signals to and from cells in tissues involves the integration of the ECM. Different cartilage types have a distinct overall ECM molecular composition, that is spatially highly heterogeneous. The heterogeneity in the ratio of ECM molecules is different in cartilage tissues and regions and leads to a depth-dependent non-uniform compressive strain transfer and alters the magnitude of forces sensed by cells in articular and fibrocartilage, influencing chondrocyte metabolism and biochemical response.

As our understanding of how strain and force are transferred through cartilage tissue grows, it is evident that it is a multiscale process. The influence of matrix molecule interaction and distribution is not well understood, and even though single cell responses to mechanical stimuli are well studied, there is a lack of understanding of the long term effects. It will be important to link the cell response to the tissue scale forces and longitudinally investigate remodelling over a longer time span.

Investigation of multiscale strain transfer would further our understanding of the complex mechanisms of mechanobiology and remodelling in different cartilage tissues, not only load bearing types. Furthermore, it would increase our knowledge about native cartilage tissue, providing a benchmark by which to compare tissue engineered constructs and feed into the development of effective treatment strategies to address cartilage pathologies.

\section{AUTHOR CONTRIBUTIONS}

$\mathrm{MB}, \mathrm{SL}$, and $\mathrm{KS}$ contributed to conception and design of the review. MB performed the literature review and wrote the first draft of the manuscript. All authors contributed to manuscript revision, read, and approved the submitted version.

\section{FUNDING}

This work was supported by The University of Melbourne.

\section{ACKNOWLEDGMENTS}

We thank Brooke Farrugia for providing the illustrations created with BioRender.com. 


\section{REFERENCES}

Alexopoulos, L. G., Haider, M. A., Vail, T. P., and Guilak, F. (2003). Alterations in the Mechanical Properties of the Human Chondrocyte Pericellular Matrix with Osteoarthritis. J. Biomech. Eng. 125 (3), 323-333. doi:10.1115/1.1579047

Alexopoulos, L. G., Youn, I., Bonaldo, P., and Guilak, F. (2009). Developmental and Osteoarthritic Changes inCol6al-Knockout Mice: Biomechanics of Type VI Collagen in the Cartilage Pericellular Matrix. Arthritis Rheum. 60 (3), 771-779. doi:10.1002/art.24293

Amis, A. (2010). ID McDermott, SD Masouros, AMJ Bull, and AA Amis. The Meniscus 91 (96), 11. doi:10.1007/978-3-642-02450-4_1.2

Athanasiou, K. A., Darling, E. M., and Hu, J. C. (2009). Articular Cartilage Tissue engineeringSynthesis Lectures on Tissue Engineering. Synth. Lectures Tissue Eng. 1 (1), 1-182. doi:10.2200/s00212edlv01y200910tis003

Aufderheide, A. C., and Athanasiou, K. A. (2006). A Direct Compression Stimulator for Articular Cartilage and Meniscal Explants. Ann. Biomed. Eng. 34 (9), 1463-1474. doi:10.1007/s10439-006-9157-x

Benya, P. D. (1988). Modulation and Reexpression of the Chondrocyte Phenotype; Mediation by Cell Shape and Microfilament Modification. Path Immunopathol Res. 7 (1-2), 51-54. doi:10.1159/000157093

Blain, E. J., Gilbert, S. J., Hayes, A. J., and Duance, V. C. (2006). Disassembly of the Vimentin Cytoskeleton Disrupts Articular Cartilage Chondrocyte Homeostasis. Matrix Biol. 25 (7), 398-408. doi:10.1016/j.matbio.2006.06.002

Bonnevie, E. D., Delco, M. L., Bartell, L. R., Jasty, N., Cohen, I., Fortier, L. A., et al. (2018). Microscale Frictional Strains Determine Chondrocyte Fate in Loaded Cartilage. J. Biomech. 74, 72-78. doi:10.1016/j.jbiomech.2018. 04.020

Bos, E. J., Pluemeekers, M., Helder, M., Kuzmin, N., van der Laan, K., Groot, M.-L., et al. (2018). Structural and Mechanical Comparison of Human Ear, Alar, and Septal Cartilage. Plast. Reconstr. Surg. - Glob. Open 6 (1), e1610. doi:10.1097/ GOX.0000000000001610

Breuls, R. G. M., Sengers, B. G., Oomens, C. W. J., Bouten, C. V. C., and Baaijens, F. P. T. (2002). Predicting Local Cell Deformations in Engineered Tissue Constructs: a Multilevel Finite Element Approach. J. Biomech. Eng. 124 (2), 198-207. doi:10.1115/1.1449492

Carlson, A. K., McCutchen, C. N., and June, R. K. (2017). Mechanobiological Implications of Articular Cartilage Crystals. Curr. Opin. Rheumatol. 29 (2), 157-162. doi:10.1097/BOR.0000000000000368

Chang, B., Reighard, C., Flanagan, C., Hollister, S., and Zopf, D. (2020). Evaluation of Human Nasal Cartilage Nonlinear and Rate Dependent Mechanical Properties. J. Biomech. 100, 109549. doi:10.1016/j.jbiomech.2019.109549

Chen, J., Zhu, X., Xu, Y., Tang, Y., Xiong, S., Zhuo, S., et al. (2014). Stereoscopic Visualization and Quantification of Auricular Cartilage Regeneration in Rabbits Using Multiphoton Microscopy. Scanning 36 (5), 540-546. doi:10.1002/sca. 21153

Chen, S. S., Falcovitz, Y. H., Schneiderman, R., Maroudas, A., and Sah, R. L. (2001). Depth-dependent Compressive Properties of normal Aged Human Femoral Head Articular Cartilage: Relationship to Fixed Charge Density. Osteoarthritis and Cartilage 9 (6), 561-569. doi:10.1053/joca.2001.0424

Chery, D. R., Han, B., Li, Q., Zhou, Y., Heo, S.-J., Kwok, B., et al. (2020). Early Changes in Cartilage Pericellular Matrix Micromechanobiology Portend the Onset of post-traumatic Osteoarthritis. Acta Biomater. 111, 267-278. doi:10. 1016/j.actbio.2020.05.005

Chung, C., Erickson, I. E., Mauck, R. L., and Burdick, J. A. (2008). Differential Behavior of Auricular and Articular Chondrocytes in Hyaluronic Acid Hydrogels. Tissue Eng. A 14 (7), 1121-1131. doi:10.1089/tea.2007.029110. 1089/ten.tea.2007.0291

Coleman, J. L., Widmyer, M. R., Leddy, H. A., Utturkar, G. M., Spritzer, C. E., Moorman, C. T., et al. (2013). Diurnal Variations in Articular Cartilage Thickness and Strain in the Human Knee. J. Biomech. 46 (3), 541-547. doi:10.1016/j.jbiomech.2012.09.013

Culav, E. M., Clark, C. H., and Merrilees, M. J. (1999). Connective Tissues: Matrix Composition and its Relevance to Physical Therapy. Phys. Ther. 79 (3), 308-319. doi:10.1093/ptj/79.3.308

D’Andrea, P., Calabrese, A., Capozzi, I., Grandolfo, M., Tonon, R., and Vittur, F. (2000). Intercellular Ca2+ Waves in Mechanically Stimulated Articular Chondrocytes. Biorheology 37 (1-2), 75-83.
Danalache, M., Jacobi, L. F., Schwitalle, M., and Hofmann, U. K. (2019). Assessment of Biomechanical Properties of the Extracellular and Pericellular Matrix and Their Interconnection throughout the Course of Osteoarthritis. J. Biomech. 97, 109409. doi:10.1016/j.jbiomech.2019.109409

Darling, E. M., Wilusz, R. E., Bolognesi, M. P., Zauscher, S., and Guilak, F. (2010). Spatial Mapping of the Biomechanical Properties of the Pericellular Matrix of Articular Cartilage Measured In Situ via Atomic Force Microscopy. Biophysical J. 98 (12), 2848-2856. doi:10.1016/j.bpj.2010.03.037

Durrant, L. A., Archer, C. W., Benjamin, M., and Ralphs, J. R. (1999). Organisation of the Chondrocyte Cytoskeleton and its Response to Changing Mechanical Conditions in Organ Culture. J. Anat. 194, 343-353. doi:10.1046/j.1469-7580. 1999.19430343.x

Eckstein, F., Tieschky, M., Faber, S., Englmeier, K.-H., and Reiser, M. (1999). Functional Analysis of Articular Cartilage Deformation, Recovery, and Fluid Flow Following Dynamic Exercise In Vivo. Anat. Embryol. 200(4), 419-424. doi:10.1007/s004290050291

Eggli, P. S., Hunzinker, E. B., and Schenk, R. K. (1988). Quantitation of Structural Features Characterizing Weight- and Less-Weight-Bearing Regions in Articular Cartilage: A Stereological Analysis of Medical Femoral Condyles in Young Adult Rabbits. Anat. Rec. 222 (3), 217-227. doi:10.1002/ar.1092220302

Erne, O. K., Reid, J. B., Ehmke, L. W., Sommers, M. B., Madey, S. M., and Bottlang, M. (2005). Depth-dependent Strain of Patellofemoral Articular Cartilage in Unconfined Compression. J. Biomech. 38 (4), 667-672. doi:10.1016/j.jbiomech. 2004.04.005

Eyre, D. (2002). Collagen of Articular Cartilage. Arthritis Res. 4(1), 30-35. doi:10. $1186 /$ ar380

Fithian, D. C., Kelly, M. A., and Mow, V. C. (1990). Material Properties and Structure-Function Relationships in the Menisci. Clin. Orthopaedics Relat. Res. 252, 19-31. doi:10.1097/00003086-199003000-00004

Fitzgerald, J. B., Jin, M., Chai, D. H., Siparsky, P., Fanning, P., and Grodzinsky, A. J. (2008). Shear- and Compression-Induced Chondrocyte Transcription Requires MAPK Activation in Cartilage Explants. J. Biol. Chem. 283 (11), 6735-6743. doi:10.1074/jbc.M708670200

Fox, A. J. S., Wanivenhaus, F., Burge, A. J., Warren, R. F., and Rodeo, S. A. (2015). The Human Meniscus: a Review of Anatomy, Function, Injury, and Advances in Treatment. Clin. Anat. 28 (2), 269-287. doi:10.1002/ca.22456

Frantz, C., Stewart, K. M., and Weaver, V. M. (2010). The Extracellular Matrix at a Glance. J. Cel Sci 123 (Pt 24), 4195-4200. doi:10.1242/jcs.023820

Fukubayashi, T., and Kurosawa, H. (1980). "The Contact Area and Pressure Distribution Pattern of the Knee:A Study of Normal and Osteoarthrotic Knee Joints." Acta Orthopaedica Scand. 51(6): 871-879. doi:10.3109/ 17453678008990887

Gilbert, S. J., and Blain, E. J. (2018). Cartilage Mechanobiology: How Chondrocytes Respond to Mechanical Load. Mechanobiology Health Dis. 1, 99-126. doi:10. 1016/b978-0-12-812952-4.00004-0

Gilchrist, C. L., Witvoet-Braam, S. W., Guilak, F., and Setton, L. A. (2007). Measurement of Intracellular Strain on Deformable Substrates with Texture Correlation. J. Biomech. 40 (4), 786-794. doi:10.1016/j.jbiomech.2006.03.013

Gomes, R., Kirn-Safran, C., Farach-Carson, M. C., and Carson, D. D. (2002). Perlecan: an Important Component of the Cartilage Pericellular Matrix. J. Musculoskelet. Neuronal Interact 2 (6), 511-516.

Guilak, F. (1995). Compression-induced Changes in the Shape and Volume of the Chondrocyte Nucleus. J. Biomech. 28 (12), 1529-1541. doi:10.1016/00219290(95)00100-x

Guilak, F., and Alexopoulos, L. G., Upton, M. L., Youn, I., and Choi, J. B., Cao, L., et al. (2006). The Pericellular Matrix as a Transducer of Biomechanical and Biochemical Signals in Articular Cartilage. Ann. N.Y Acad. Sci. 1068, 498-512. doi:10.1196/annals.1346.011

Guilak, F., Ratcliffe, A., and Mow, V. C. (1995). Chondrocyte Deformation and Local Tissue Strain in Articular Cartilage: A Confocal Microscopy Study. J. Orthop. Res. 13 (3), 410-421. doi:10.1002/jor.1100130315

Guilak, F., Tedrow, J. R., and Burgkart, R. (2000). Viscoelastic Properties of the Cell Nucleus. Biochem. Biophysical Res. Commun. 269 (3), 781-786. doi:10.1006/ bbrc.2000.2360

Guilak, F., Zell, R. A., Erickson, G. R., Grande, D. A., Rubin, C. T., McLeod, K. J., et al. (1999). Mechanically Induced Calcium Waves in Articular Chondrocytes Are Inhibited by Gadolinium and Amiloride. J. Orthop. Res. 17 (3), 421-429. doi:10.1002/jor.1100170319 
Hall, A. C. (2019). The Role of Chondrocyte Morphology and Volume in Controlling Phenotype-Implications for Osteoarthritis, Cartilage Repair, and Cartilage Engineering. Curr. Rheumatol. Rep. 21 (8), 38. doi:10.1007/s11926019-0837-6

Han, W. M., Heo, S.-J., Driscoll, T. P., Delucca, J. F., McLeod, C. M., Smith, L. J., et al. (2016). Microstructural Heterogeneity Directs Micromechanics and Mechanobiology in Native and Engineered Fibrocartilage. Nat. Mater 15 (4), 477-484. doi:10.1038/nmat4520

Han, W. M., Heo, S.-J., Driscoll, T. P., Smith, L. J., Mauck, R. L., and Elliott, D. M. (2013). Macro- to Microscale Strain Transfer in Fibrous Tissues Is Heterogeneous and Tissue-specific. Biophysical J. 105 (3), 807-817. doi:10. 1016/j.bpj.2013.06.023

He, B., Wu, J. P., Chen, H. H., Kirk, T. B., and Xu, J. (2013). Elastin Fibers Display a Versatile Microfibril Network in Articular Cartilage Depending on the Mechanical Microenvironments. J. Orthop. Res. 31 (9), 1345-1353. doi:10. 1002/jor.22384

Heinegård, D. (2009). Fell-Muir Lecture: Proteoglycans and More - from Molecules to Biology. Int. J. Exp. Pathol. 90 (6), 575-586. doi:10.1111/j.1365-2613.2009. 00695.x

Heinegård, D., and Saxne, T. (2011). The Role of the Cartilage Matrix in Osteoarthritis. Nat. Rev. Rheumatol. 7 (1), 50-56. doi:10.1038/nrrheum. 2010.198

Hellio Le Graverand, M.-P., Ou, Y., Schield-yee, T., Barclay, L., Hart, D., Natsume, T., et al. (2001). The Cells of the Rabbit Meniscus: Their Arrangement, Interrelationship, Morphological Variations and Cytoarchitecture. J. Anat. 198 (Pt 5), 525-535. doi:10.1046/j.1469-7580.2000.19850525.x

Homicz, M. R., McGowan, K. B., Lottman, L. M., Beh, G., Sah, R. L., and Watson, D. (2003). A Compositional Analysis of Human Nasal Septal Cartilage. Arch. Facial Plast. Surg. 5 (1), 53-58. doi:10.1001/archfaci.5.1.53

Huang, C.-Y., Stankiewicz, A., Ateshian, G. A., and Mow, V. C. (2005). Anisotropy, Inhomogeneity, and Tension-Compression Nonlinearity of Human Glenohumeral Cartilage in Finite Deformation. J. Biomech. 38 (4), 799-809. doi:10.1016/j.jbiomech.2004.05.006

Humphrey, J. D., Dufresne, E. R., and Schwartz, M. A. (2014). Mechanotransduction and Extracellular Matrix Homeostasis. Nat. Rev. Mol. Cel Biol 15 (12), 802-812. doi:10.1038/nrm3896

Hynes, R. O. (2002). Integrins. Cell 110 (6), 673-687. doi:10.1016/s0092-8674(02) 00971-6

Ingber, D. E., Dike, L., Hansen, L., Karp, S., Liley, H., Maniotis, A., et al. (1994). Cellular Tensegrity: Exploring How Mechanical Changes in the Cytoskeleton Regulate Cell Growth, Migration, and Tissue Pattern during Morphogenesis. Mech. Eng. Cytoskeleton Develop. Biol. 150, 173-224. doi:10.1016/s00747696(08)61542-9

Irianto, J., Ramaswamy, G., Serra, R., and Knight, M. M. (2014). Depletion of Chondrocyte Primary Cilia Reduces the Compressive Modulus of Articular Cartilage. J. Biomech. 47 (2), 579-582. doi:10.1016/j.jbiomech.2013.11.040

Irwin, R. M., Gao, T., Boys, A. J., Ortved, K., Cohen, I., and Bonassar, L. J. (2021). Microscale Strain Mapping Demonstrates the Importance of Interface Slope in the Mechanics of Cartilage Repair. J. Biomech. 114, 110159. doi:10.1016/j. jbiomech.2020.110159

Jang, K. W., Buckwalter, J. A., and Martin, J. A. (2014). Inhibition of Cell-Matrix Adhesions Prevents Cartilage Chondrocyte Death Following Impact Injury. J. Orthop. Res. 32 (3), 448-454. doi:10.1002/jor.22523

Jessop, Z. M., Javed, M., Otto, I. A., Combellack, E. J., Morgan, S., Breugem, C. C., et al. (2016). Combining Regenerative Medicine Strategies to Provide Durable Reconstructive Options: Auricular Cartilage Tissue Engineering. Stem Cel Res Ther 7, 19. doi:10.1186/s13287-015-0273-0

Keith, D. A., Paz, A., Gallop, P. M., and Glimcher, M. J. (1977). Histologic and Biochemical Identification and Characterization of an Elastin in Cartilage. J. Histochem. Cytochem. 25 (10), 1154-1162. doi:10.1177/25.10.72098

Khan, I., Gilbert, S., Singhrao, S., Duance, V., and Archer, C. (2008). Evaluation of the Reasons for Failure of Integration during Cartilage Repair. A Reviewe. Eur. Cell Mater., 16, 26-39. doi:10.22203/eCM.v016a04

Khoshgoftar, M., Torzilli, P. A., and Maher, S. A. (2017). Influence of the Pericellular and Extracellular Matrix Structural Properties on Chondrocyte Mechanics. J. Orthop. Res. 36 (2), 721-729. doi:10.1002/jor.23774

Klika, V., Whiteley, J. P., Brown, C. P., and Gaffney, E. A. (2019). The Combined Impact of Tissue Heterogeneity and Fixed Charge for Models of Cartilage: the
One-Dimensional Biphasic Swelling Model Revisited. Biomech. Model. Mechanobiol 18 (4), 953-968. doi:10.1007/s10237-019-01123-7

Knight, M. M., Bomzon, Z., Kimmel, E., Sharma, A. M., Lee, D. A., and Bader, D. L. (2006). Chondrocyte Deformation Induces Mitochondrial Distortion and Heterogeneous Intracellular Strain fields. Biomech. Model. Mechanobiol 5 (2-3), 180-191. doi:10.1007/s10237-006-0020-7

Kolaczek, S., Hewison, C., Caterine, S., Ragbar, M. X., Getgood, A., and Gordon, K. D. (2016). Analysis of 3D Strain in the Human Medial Meniscus. J. Mech. Behav. Biomed. Mater. 63, 470-475. doi:10.1016/j.jmbbm.2016.06.001

Kwon, H., Paschos, N. K., Hu, J. C., and Athanasiou, K. (2016). Articular Cartilage Tissue Engineering: the Role of Signaling Molecules. Cell. Mol. Life Sci. 73 (6), 1173-1194. doi:10.1007/s00018-015-2115-8

Lai, J. H., and Levenston, M. E. (2010). Meniscus and Cartilage Exhibit Distinct Intra-tissue Strain Distributions under Unconfined Compression. Osteoarthritis and Cartilage 18 (10), 1291-1299. doi:10.1016/j.joca.2010.05.020

Lee, W., Guilak, F., and Liedtke, W. (2017). Role of Piezo Channels in Joint Health and Injury. Curr. Top. Membr. 79, 263-273. doi:10.1016/bs.ctm.2016.10.003

Lee, W., Leddy, H. A., Chen, Y., Lee, S. H., Zelenski, N. A., McNulty, A. L., et al. (2014). Synergy between Piezo1 and Piezo2 Channels Confers High-Strain Mechanosensitivity to Articular Cartilage. Proc. Natl. Acad. Sci. USA 111 (47), E5114-E5122. doi:10.1073/pnas.1414298111

Liu, F., Kozanek, M., Hosseini, A., Van de Velde, S. K., Gill, T. J., Rubash, H. E., et al. (2010). In Vivo tibiofemoral Cartilage Deformation during the Stance Phase of Gait. J. Biomech. 43 (4), 658-665. doi:10.1016/j.jbiomech.2009.10.028

Lu, P., Takai, K., Weaver, V. M., and Werb, Z. (2011). Extracellular Matrix Degradation and Remodeling in Development and Disease. Cold Spring Harbor Perspect. Biol. 3 (12), a005058. doi:10.1101/cshperspect.a005058

Lu, X. L., Mow, V. C., and Guo, X. E. (2009). Proteoglycans and Mechanical Behavior of Condylar Cartilage. J. Dent Res. 88 (3), 244-248. doi:10.1177/ 0022034508330432

Lucchinetti, E., Bhargava, M. M., and Torzilli, P. A. (2004). The Effect of Mechanical Load on Integrin Subunits ?5 and ?1 in Chondrocytes from Mature and Immature Cartilage Explants. Cel Tissue Res. 315 (3), 385-391. doi:10.1007/s00441-003-0836-8

Makris, E. A., Hadidi, P., and Athanasiou, K. A. (2011). The Knee Meniscus: Structure-Function, Pathophysiology, Current Repair Techniques, and Prospects for Regeneration. Biomaterials 32 (30), 7411-7431. doi:10.1016/j. biomaterials.2011.06.037

Mansfield, J. C., Bell, J. S., and Winlove, C. P. (2015). The Micromechanics of the Superficial Zone of Articular Cartilage. Osteoarthritis and Cartilage 23 (10), 1806-1816. doi:10.1016/j.joca.2015.05.030

Mansfield, J., Yu, J., Attenburrow, D., Moger, J., Tirlapur, U., Urban, J., et al. (2009). The Elastin Network: its Relationship with Collagen and Cells in Articular Cartilage as Visualized by Multiphoton Microscopy. J. Anat. 215 (6), 682-691. doi:10.1111/j.1469-7580.2009.01149.x

Mansour, J. M. (2003). Biomechanics of Cartilage. Kinesiol. Mech. Pathomech. Hum. Mov. 2: 66-79.

Marcelino, J., and McDevitt, C. A. (1995). Attachment of Articular Cartilage Chondrocytes to the Tissue Form of Type VI Collagen. Biochim. Biophys. Acta (Bba) - Protein Struct. Mol. Enzymol. 1249 (2), 180-188. doi:10.1016/01674838(95)00026-q

Martins, R. P., Finan, J. D., Farshid, G., and Lee, D. A. (2012). Mechanical Regulation of Nuclear Structure and Function. Annu. Rev. Biomed. Eng. 14, 431-455. doi:10.1146/annurev-bioeng-071910-124638

McDermott, I. D. (2010). "Anatomy"in The Meniscus. Editors P Beaufils and R Verdonk (Berlin, Heidelberg: Springer Berlin Heidelberg), 11-18.

McDermott, I. D., Masouros, S. D., and Amis, A. A. (2008). Biomechanics of the Menisci of the Knee. Curr. Orthopaedics 22 (3), 193-201. doi:10.1016/j.cuor. 2008.04.005

McGlashan, S. R., Jensen, C. G., and Poole, C. A. (2006). Localization of Extracellular Matrix Receptors on the Chondrocyte Primary Cilium. J. Histochem. Cytochem. 54 (9), 1005-1014. doi:10.1369/jhc.5A6866.2006

McHenry, J. A., Zielinska, B., and Haut Donahue, T. L. (2006). Proteoglycan Breakdown of Meniscal Explants Following Dynamic Compression Using a Novel Bioreactor. Ann. Biomed. Eng. 34 (11), 1758-1766. doi:10.1007/s10439006-9178-5

McNulty, A. L., and Guilak, F. (2015). Mechanobiology of the Meniscus. J. Biomech. 48 (8), 1469-1478. doi:10.1016/j.jbiomech.2015.02.008 
Millward-Sadler, S. J., and Salter, D. M. (2004). Integrin-dependent Signal Cascades in Chondrocyte Mechanotransduction. Ann. Biomed. Eng. 32 (3), 435-446. doi:10.1023/b:abme.0000017538.72511.48

Millward-Sadler, S. J., Wright, M. O., Lee, H.-S., Caldwell, H., Nuki, G., and Salter, D. M. (2000). Altered Electrophysiological Responses to Mechanical Stimulation and Abnormal Signalling through $\alpha 5 \beta 1$ Integrin in Chondrocytes from Osteoarthritic Cartilage. Osteoarthritis and Cartilage 8 (4), 272-278. doi:10.1053/joca.1999.0301

Mobasheri, A., Carter, S D., Martín-Vasallo, P., and Shakibaei, M. (2002). Integrins and Stretch Activated Ion Channels; Putative Components of Functional Cell Surface Mechanoreceptors in Articular Chondrocytes. Cel Biol. Int. 26 (1), 1-18. doi:10.1006/cbir.2001.0826

Mofrad, M., Mofrad, M. R. K., and Kamm, R. D. (2010). Cellular Mechanotransduction : Diverse Perspectives from Molecules to Tissues. Cambridge: Cambridge University Press.

Nalesso, G., Sherwood, J., Bertrand, J., Pap, T., Ramachandran, M., De Bari, C., et al. (2011). WNT-3A Modulates Articular Chondrocyte Phenotype by Activating Both Canonical and Noncanonical Pathways. J. Cel Biol 193 (3), 551-564. doi:10.1083/jcb.201011051

Nia, H. T., Gauci, S. J., Azadi, M., Hung, H.-H., Frank, E., Fosang, A. J., et al. (2015). High-bandwidth AFM-Based Rheology Is a Sensitive Indicator of Early Cartilage Aggrecan Degradation Relevant to Mouse Models of Osteoarthritis. J. Biomech. 48 (1), 162-165. doi:10.1016/j.jbiomech. 2014.11.012

Nickien, M., Thambyah, A., and Broom, N. (2013). How Changes in Fibril-Level Organization Correlate with the Macrolevel Behavior of Articular Cartilage. Wires Syst. Biol. Med. 5 (4), 495-509. doi:10.1002/wsbm.1220

Nimeskern, L., Pleumeekers, M. M., Pawson, D. J., Koevoet, W. L. M., Lehtoviita, I., Soyka, M. B., et al. (2015). Mechanical and Biochemical Mapping of Human Auricular Cartilage for Reliable Assessment of Tissue-Engineered Constructs. J. Biomech. 48 (10), 1721-1729. doi:10.1016/j.jbiomech.2015.05.019

Nimeskern, L., Utomo, L., Lehtoviita, I., Fessel, G., Snedeker, J. G., van Osch, G. J. V. M., et al. (2016). Tissue Composition Regulates Distinct Viscoelastic Responses in Auricular and Articular Cartilage. J. Biomech. 49 (3), 344-352. doi:10.1016/j.jbiomech.2015.12.032

O'Conor, C. J., Leddy, H. A., Benefield, H. C., Liedtke, W. B., and Guilak, F. (2014). TRPV4-mediated Mechanotransduction Regulates the Metabolic Response of Chondrocytes to Dynamic Loading. Proc. Natl. Acad. Sci. 111 (4), 1316-1321. doi:10.1073/pnas.1319569111

Parkkinen, J. J., Lammi, M. J., Inkinen, R., Jortikka, M., Tammi, M., Virtanen, I., et al. (1995). Influence of Short-Term Hydrostatic Pressure on Organization of Stress Fibers in Cultured Chondrocytes. J. Orthop. Res. 13 (4), 495-502. doi:10. 1002/jor.1100130404

Phan, M. N., Leddy, H. A., Votta, B. J., Kumar, S., Levy, D. S., Lipshutz, D. B., et al. (2009). Functional Characterization of TRPV4 as an Osmotically Sensitive Ion Channel in Porcine Articular Chondrocytes. Arthritis Rheum. 60 (10), 3028-3037. doi:10.1002/art.24799

Pingguan-Murphy, B., El-Azzeh, M., Bader, D. L., and Knight, M. M. (2006). Cyclic Compression of Chondrocytes Modulates a Purinergic Calcium Signalling Pathway in a Strain Rate- and Frequency-dependent Manner. J. Cel. Physiol. 209 (2), 389-397. doi:10.1002/jcp.20747

Poole, A. R., Kojima, T., Yasuda, T., Mwale, F., Kobayashi, M., and Laverty, S. (2001). Composition and Structure of Articular Cartilage. Clin. Orthopaedics Relat. Res. 391 (Suppl. 1), S26-S33. doi:10.1097/00003086-200110001-00004

Poole, C. A. (1997). Review. Articular Cartilage Chondrons: Form, Function and Failure. J. Anat. 191 (Pt 1), 1-13. doi:10.1046/j.1469-7580.1997.19110001.x

Quinn, T. M., Grodzinsky, A. J., Buschmann, M. D., Kim, Y. J., and Hunziker, E. B. (1998). Mechanical Compression Alters Proteoglycan Deposition and Matrix Deformation Around Individual Cells in Cartilage Explants. J. Cel Sci. 111, 573-583. doi:10.1242/jcs.111.5.573

Quinn, T. M., Häuselmann, H.-J., Shintani, N., and Hunziker, E. B. (2013). Cell and Matrix Morphology in Articular Cartilage from Adult Human Knee and Ankle Joints Suggests Depth-Associated Adaptations to Biomechanical and Anatomical Roles. Osteoarthritis and Cartilage 21 (12), 1904-1912. doi:10. 1016/j.joca.2013.09.011

Responte, D. J., Natoli, R. M., and Athanasiou, K. A. (2007). Collagens of Articular Cartilage: Structure, Function, and Importance in Tissue Engineering. Crit. Rev. Biomed. Eng. 35 (5), 363-411. doi:10.1615/critrevbiomedeng.v35.i5.20
Roberts, S. R., Knight, M. M., Lee, D. A., and Bader, D. L. (2001). Mechanical Compression Influences Intracellular Ca2+ Signaling in Chondrocytes Seeded in Agarose Constructs. J. Appl. Physiol. 90 (4), 1385-1391. doi:10.1152/jappl. 2001.90.4.1385

Roth, V., and Mow, V. C. (1980). The Intrinsic Tensile Behavior of the Matrix of Bovine Articular Cartilage and its Variation with ageThe Journal of Bone and Joint Surgery. J. Bone Jt. Surg. 62 (7), 1102-1117. doi:10.2106/00004623198062070-00007

Ruhlen, R., and Marberry, K. (2014). The Chondrocyte Primary Cilium. Osteoarthritis and Cartilage 22 (8), 1071-1076. doi:10.1016/j.joca.2014.05.011

Sanchez-Adams, J., Wilusz, R. E., and Guilak, F. (2013). Atomic Force Microscopy Reveals Regional Variations in the Micromechanical Properties of the Pericellular and Extracellular Matrices of the Meniscus. J. Orthop. Res. 31 (8), 1218-1225. doi:10.1002/jor.22362

Sauter, E., Buckwalter, J. A., McKinley, T. O., and Martin, J. A. (2012). Cytoskeletal Dissolution Blocks Oxidant Release and Cell Death in Injured Cartilage. J. Orthop. Res. 30 (4), 593-598. doi:10.1002/jor.21552

Scholtes, S., Krämer, E., Weisser, M., Roth, W., Luginbühl, R., Grossner, T., et al. (2018). Global Chondrocyte Gene Expression after a Single Anabolic Loading Period: Time Evolution and Re-inducibility of Mechano-responses. J. Cel Physiol 233 (1), 699-711. doi:10.1002/jcp.25933

Shu, C. C., Jackson, M. T., Smith, M. M., Smith, S. M., Penm, S., Lord, M. S., et al. (2016). Ablation of Perlecan Domain 1 Heparan Sulfate Reduces Progressive Cartilage Degradation, Synovitis, and Osteophyte Size in a Preclinical Model of Posttraumatic Osteoarthritis. Arthritis Rheumatol. 68 (4), 868-879. doi:10. $1002 /$ art.39529

Sophia Fox, A. J., Bedi, A., and Rodeo, S. A. (2009). The Basic Science of Articular Cartilage: Structure, Composition, and Function. Sports Health 1 (6), 461-468. doi:10.1177/1941738109350438

Steklov, N., Srivastava, A., Sung, K. L., Chen, P. C., Lotz, M. K., and D’Lima, D. D. (2009). Aging-related Differences in Chondrocyte Viscoelastic Properties. Mol. Cel Biomech 6 (2), 113-119.

Szafranski, J. D., Grodzinsky, A. J., Burger, E., Gaschen, V., Hung, H.-H., and Hunziker, E. B. (2004). Chondrocyte Mechanotransduction: Effects of Compression on Deformation of Intracellular Organelles and Relevance to Cellular Biosynthesis. Osteoarthritis and Cartilage 12 (12), 937-946. doi:10. 1016/j.joca.2004.08.004

Takada, S., Fujimori, S., Shinozuka, T., Takada, R., and Mii, Y. (2017). Differences in the Secretion and Transport of Wnt Proteins. J. Biochem. 161 (1), 1-7. doi:10. 1093/jb/mvw071

Tamamura, Y., Otani, T., Kanatani, N., Koyama, E., Kitagaki, J., Komori, T., et al. (2005). Developmental Regulation of Wnt/ $\beta$-Catenin Signals Is Required for Growth Plate Assembly, Cartilage Integrity, and Endochondral Ossification. J. Biol. Chem. 280 (19), 19185-19195. doi:10.1074/jbc.M414275200

Tanska, P., Venäläinen, M. S., Erdemir, A., and Korhonen, R. K. (2020). A Multiscale Framework for Evaluating Three-Dimensional Cell Mechanics in Fibril-Reinforced Poroelastic Tissues with Anatomical Cell Distribution Analysis of Chondrocyte Deformation Behavior in Mechanically Loaded Articular Cartilage. J. Biomech. 101, 109648. doi:10.1016/j.jbiomech.2020. 109648

Theocharis, A. D., Skandalis, S. S., Gialeli, C., and Karamanos, N. K. (2016). Extracellular Matrix Structure. Adv. Drug Deliv. Rev. 97, 4-27. doi:10.1016/j. addr.2015.11.001

Thielen, N., van der Kraan, P., and van Caam, A. (2019). TGF $\beta / B M P$ Signaling Pathway in Cartilage Homeostasis. Cells 8 (9), 969. doi:10.3390/cells8090969

Trickey, W. R., Vail, T. P., and Guilak, F. (2004). The Role of the Cytoskeleton in the Viscoelastic Properties of Human Articular Chondrocytes. J. Orthop. Res. 22 (1), 131-139. doi:10.1016/s0736-0266(03)00150-510.1016/s0736-0266(03) 0150-5

Upton, M. L., Gilchrist, C. L., Guilak, F., and Setton, L. A. (2008). Transfer of Macroscale Tissue Strain to Microscale Cell Regions in the Deformed Meniscus. Biophysical J. 95 (4), 2116-2124. doi:10.1529/biophysj.107.126938

Vincent, T. L., McLean, C. J., Full, L. E., Peston, D., and Saklatvala, J. (2007). FGF-2 Is Bound to Perlecan in the Pericellular Matrix of Articular Cartilage, where it Acts as a Chondrocyte Mechanotransducer. Osteoarthritis and Cartilage 15 (7), 752-763. doi:10.1016/j.joca.2007.01.021

Wang, N. (2017). Review of Cellular Mechanotransduction. J. Phys. D: Appl. Phys. 50 (23), 233002. doi:10.1088/1361-6463/aa6e18 
Wann, A. K. T., Zuo, N., Haycraft, C. J., Jensen, C. G., Poole, C. A., McGlashan, S. R., et al. (2012). Primary Cilia Mediate Mechanotransduction through Control of ATP-induced Ca2+signaling in Compressed Chondrocytes. FASEB j. 26 (4), 1663-1671. doi:10.1096/fj.11-193649

Wilusz, R. E., DeFrate, L. E., and Guilak, F. (2012). A Biomechanical Role for Perlecan in the Pericellular Matrix of Articular Cartilage. Matrix Biol. 31 (6), 320-327. doi:10.1016/j.matbio.2012.05.002

Wilusz, R. E., Sanchez-Adams, J., and Guilak, F. (2014). The Structure and Function of the Pericellular Matrix of Articular Cartilage. Matrix Biol. 39, 25-32. doi:10.1016/j.matbio.2014.08.009

Wolfenson, H., Lavelin, I., and Geiger, B. (2013). Dynamic Regulation of the Structure and Functions of Integrin Adhesions. Develop. Cel 24 (5), 447-458. doi:10.1016/j.devcel.2013.02.012

Wong, B. L., Bae, W. C., Chun, J., Gratz, K. R., Lotz, M., and Robert, L. S. (2008). Biomechanics of Cartilage Articulation: Effects of Lubrication and Degeneration on Shear Deformation. Arthritis Rheum. 58 (7), 2065-2074. doi:10.1002/art.23548

Wong, M., and Carter, D. R. (2003). Articular Cartilage Functional Histomorphology and Mechanobiology: a Research Perspective. Bone 33 (1), 1-13. doi:10.1016/s8756-3282(03)00083-8

Wong, M., Wuethrich, P., Eggli, P., and Hunziker, E. (1996). Zone-specific Cell Biosynthetic Activity in Mature Bovine Articular Cartilage: A New Method Using Confocal Microscopic Stereology and Quantitative Autoradiography. J. Orthop. Res. 14(3), 424-432. doi:10.1002/jor.1100140313

Yeh, A. T., Hammer-Wilson, M. J., Van Sickle, D. C., Benton, H. P., Zoumi, A., Tromberg, B. J., et al. (2005). Nonlinear Optical Microscopy of Articular Cartilage. Osteoarthritis and Cartilage 13 (4), 345-352. doi:10.1016/j.joca. 2004.12.007

Yu, J., and Urban, J. P. G. (2010). The Elastic Network of Articular Cartilage: an Immunohistochemical Study of Elastin Fibres and Microfibrils. J. Anat. 216 (4), 533-541. doi:10.1111/j.1469-7580.2009.01207.x

Yuasa, T., Otani, T., Koike, T., Iwamoto, M., and Enomoto-Iwamoto, M. (2008). Wnt/ $\beta$-catenin Signaling Stimulates Matrix Catabolic Genes and Activity in Articular Chondrocytes: its Possible Role in Joint Degeneration. Lab. Invest. 88 (3), 264-274. doi:10.1038/labinvest.3700747

Zelenski, N. A., Leddy, H. A., Sanchez-Adams, J., Zhang, J., Bonaldo, P., Liedtke, W., et al. (2015). Type VI Collagen Regulates Pericellular Matrix Properties, Chondrocyte Swelling, and Mechanotransduction in Mouse Articular Cartilage. Arthritis Rheumatol. 67 (5), 1286-1294. doi:10.1002/art.39034
Zhou, Y., Lv, M., Li, T., Zhang, T., Duncan, R., Wang, L., et al. (2019). Spontaneous Calcium Signaling of Cartilage Cells: from Spatiotemporal Features to Biophysical Modeling. FASEB j. 33 (4), 4675-4687. doi:10. 1096/fj.201801460R

Zhou, Y., Millward-Sadler, S. J., Lin, H., Robinson, H., Goldring, M., Salter, D. M., et al. (2007). Evidence for JNK-dependent Up-Regulation of Proteoglycan Synthesis and for Activation of JNK1 Following Cyclical Mechanical Stimulation in a Human Chondrocyte Culture Model. Osteoarthritis and Cartilage 15 (8), 884-893. doi:10.1016/j.joca.2007. 02.001

Zhu, M., Chen, M., Zuscik, M., Wu, Q., Wang, Y. J., Rosier, R. N., et al. (2008). Inhibition of $\beta$-catenin Signaling in Articular Chondrocytes Results in Articular Cartilage Destruction. Arthritis Rheum. 58 (7), 2053-2064. doi:10.1002/art. 23614

Zhu, M., Tang, D., Wu, Q., Hao, S., Chen, M., Xie, C., et al. (2009). Activation of $\beta$ Catenin Signaling in Articular Chondrocytes Leads to Osteoarthritis-like Phenotype in Adult $\beta$-Catenin Conditional Activation Mice. J. Bone Mineral Res. 24 (1), 12-21. doi:10.1359/jbmr.080901

Zielinska, B., Killian, M., Kadmiel, M., Nelsen, M., and Haut Donahue, T. L. (2009). Meniscal Tissue Explants Response Depends on Level of Dynamic Compressive Strain. Osteoarthritis and Cartilage 17 (6), 754-760. doi:10.1016/j.joca.2008. 11.018

Conflict of Interest: The authors declare that the research was conducted in the absence of any commercial or financial relationships that could be construed as a potential conflict of interest.

Publisher's Note: All claims expressed in this article are solely those of the authors and do not necessarily represent those of their affiliated organizations, or those of the publisher, the editors and the reviewers. Any product that may be evaluated in this article, or claim that may be made by its manufacturer, is not guaranteed or endorsed by the publisher.

Copyright $(2022$ Boos, Lamandé and Stok. This is an open-access article distributed under the terms of the Creative Commons Attribution License (CC BY). The use, distribution or reproduction in other forums is permitted, provided the original author(s) and the copyright owner(s) are credited and that the original publication in this journal is cited, in accordance with accepted academic practice. No use, distribution or reproduction is permitted which does not comply with these terms. 